\title{
Randomized controlled trial of a brief Internet-based intervention for families of Veterans with posttraumatic stress disorder
}

\author{
Alejandro Interian, PhD; ${ }^{1 *}$ Anna Kline, PhD; ${ }^{1}$ Deborah Perlick, PhD $;^{2-3}$ Lisa Dixon, MD, MPH; ${ }^{2,4}$ Ann Feder, \\ LCSW $;{ }^{5}$ Marc D. Weiner, PhD, JD; ${ }^{6}$ Marjorie F. Goldstein, PhD, MPH; ${ }^{7}$ Kerry Hennessy, MPH; ${ }^{6}$ Lauren St. \\ Hill, BS; ${ }^{6}$ Miklos Losonczy, MD, PhD $^{8}$ \\ ${ }^{1}$ Mental Health and Behavioral Sciences, Department of Veterans Affairs (VA) New Jersey Health Care System, Lyons, \\ NJ; and Department of Psychiatry, Robert Wood Johnson Medical School, Rutgers University, New Brunswick, NJ; \\ ${ }^{2}$ VA Veterans Integrated Service Network 3, Mental Illness Research, Education, and Clinical Center, Bronx, NY; \\ ${ }^{3}$ Department of Psychiatry, Icahn School of Medicine, Mount Sinai, New York, NY; ${ }^{4}$ Department of Psychiatry, Colum- \\ bia University, New York, NY; ${ }^{5}$ VA Veterans Integrated Service Network 3, Bronx, NY; ${ }^{6}$ Bloustein School of Planning \\ and Public Policy, Rutgers University, New Brunswick, NJ; ${ }^{7}$ National Development and Research Institutes Inc, New \\ York, NY; ${ }^{8}$ Jewish Board for Family and Child Services, Bronx, $N Y$
}

\begin{abstract}
Veterans with posttraumatic stress disorder (PTSD) and their families require resources to cope with postdeployment readjustment. Responding to this need, the current study examined a brief Internet-based intervention that provided Veterans' families with psychoeducation on postdeployment readjustment. Participants were 103 dyads of Veterans with probable PTSD and a designated family member/partner. Dyads were randomized to an intervention group, in which the family member completed the intervention, or to a control group with no intervention. Each member of the dyad completed surveys at baseline and 2 mo follow-up. Family member surveys focused on perceived empowerment, efficacy to provide support, and communication (perceived criticism and reactivity to criticism). Veteran surveys assessed perceived family support and communication. Results showed that Veterans in the intervention group reported decreases in reactivity to criticism but also decreased perceived family support. No significant differences were observed in outcomes reported by family members. This preliminary study provides an early understanding of this novel outreach program, as well as the challenges inherent with a very brief intervention. Future research can build on the current study by more closely evaluating the communication changes that occur with this form of intervention and whether greater intervention intensity is needed.
\end{abstract}

Clinical Trial Registration: ClinicalTrials.gov; "The families of heroes: An evaluation of an online educational tool": NCT01554839; https://clinicaltrials.gov/ct2/show/NCT01554839?term=NCT01554839

Key words: family communication, family support, intervention, OEF, OIF, outreach program, postdeployment, psychoeducation, PTSD, resources.

Abbreviations: ANOVA $=$ analysis of variance, $\mathrm{OEF}=$ Operation Enduring Freedom, OIF = Operation Iraqi Freedom, PCL = PTSD Checklist, PTSD = posttraumatic stress disorder, VA = Department of Veterans Affairs, VISN3 = Veterans Integrated Service Network 3.

*Address all correspondence to Alejandro Interian, PhD; VA New Jersey Healthcare System, Mental Health and Behavioral Sciences (116A), 151 Knollcroft Rd, Lyons, NJ 07939; 908-647-0180 ext 4617; fax: 908-604-5313.

Email: alejandro.interian@va.gov

http://dx.doi.org/10.1682/JRRD.2014.10.0257 


\section{INTRODUCTION}

Studies have increasingly recognized the critical role that family conflict plays in shaping the severity and course of posttraumatic stress disorder (PTSD) among servicemembers returning from Operation Iraqi Freedom (OIF) and Operation Enduring Freedom (OEF). Servicemembers who report family problems, either before or after a deployment, are at greater risk for PTSD [1]. Also, PTSD symptoms have been found to have a negative effect on readjustment, leading to difficulties with reestablishing bonds, familial roles, and household routines [2-3]. Altogether, research highlights the importance of a postdeployment environment in which family members are able to adequately understand, communicate with, and support servicemembers experiencing PTSD and other postdeployment sequelae. Interventions that can enhance this capacity among families have the potential to improve the mental health of returning OIF/OEF servicemembers.

The postdeployment period is characterized by the returning servicemember's readjustment to the home front as well as by families adapting to changes in the behavior of their returning loved one [4]. During this period, servicemembers may display symptoms of PTSD, such as poor sleep, irritability, and hypervigilance. Postdeployment may also be associated with risk-taking behaviors such as aggressive driving that were adaptive in a combat deployment but are maladaptive in a civilian context [4-5]. Families who are welcoming back their servicemembers and observe these changes need to understand these behaviors in order to provide servicemembers with support. From the servicemembers' perspective, the readjustment challenges include feeling like a guest in one's home or finding their children not responding warmly to them, difficulties that are more likely among servicemembers with PTSD [2]. Families who manage these challenges in a way that helps servicemembers maintain a sense of support are more likely to ameliorate the course of PTSD symptoms [6]. Clearly, interventions that can improve families' capacity to cope with these issues are needed.

Saltzman et al. outlined several interventions targeted to improve a family's capacity to cope with the demands of these postdeployment issues [7]. Among these is psychoeducation that improves the family's understanding of readjustment stress and PTSD. With an adequate understanding of common postdeployment complications, family members are in a better position to adaptively attribute the cause of their loved ones' difficulties. With this, they can provide the necessary support by conveying understanding and adjusting expectations [7-8].

Another mechanism to be targeted by interventions focuses on communication processes in families of returning servicemembers [7]. Adaptive communication is needed to work through postdeployment challenges. There is evidence that communication in families of returning servicemembers can be characterized by extremes ranging from avoidance [9] to overly charged communication that includes problematic displays of anger $[2,10]$. Adaptive communication techniques have long been used in couples and family therapies [11-12]. Interventions that can assist families to communicate their feelings, while also providing skills to prevent escalation of conflictual material into arguments, can enhance their capacity to work through the challenges of the postdeployment period.

Internet-based interventions have a potentially strong role to play in helping military families understand and cope with postdeployment. Health information-seeking on the Internet is widespread in the general population. An estimated 87 percent of American adults now use the Internet [13], and 72 percent sought health information on the Internet in a $1 \mathrm{yr}$ period [14]. A survey in the Veteran population reported that most respondents have Internet access and are willing to obtain health-related information online [15]. Such information-seeking has been linked to intention to initiate mental health services [16]. Given these trends, there is a need for Internetbased programs to disseminate information to military families about PTSD and postdeployment complications. While there are several face-to-face interventions for families and couples burgeoning within the Department of Veterans Affairs (VA) and the Department of Defense [e.g., 17-19], an Internet-based program would help reach those not yet engaged with these services and those who are seeking health information online.

The evidence base for Internet-based self-help interventions has been growing. Meta-analyses of such interventions report mean effect sizes in the medium range [20-21]. Particularly relevant to assisting returning servicemembers is an Internet-based intervention recently piloted to target combat-related mental distress [22]. In an uncontrolled design, participants receiving the intervention showed decreases in depression and anxiety 
symptoms. A common element of many Internet-based interventions is their duration, often spanning a period of 6 wk or more. These interventions have the advantage of improving access given their availability on the Internet. However, because of these interventions' longer duration, individuals not yet ready to fully engage in such interventions may be deterred. Thus, there remains a need for brief, Internet-based interventions for users who are engaged in Internet-based information-seeking, particularly for families of returning servicemembers.

Responding to this need, VA provided funding to develop a brief (1 h) Internet-based intervention (Family of Heroes) designed to help family members better communicate with returning Veterans with probable PTSD. By being publicly available online and short in duration, the intervention is accessible to a larger pool of users who may or may not be involved with formal services. A previous evaluation of the Family of Heroes program, based on a convenience sample, showed that family members who completed the $1 \mathrm{~h}$ training reported greater perceived efficacy to accomplish tasks targeted by the training relative to a control group who did not receive the intervention [23]. The authors of that study also reported that family members who received the intervention were more likely, relative to the control group, to report that their Veteran sought subsequent mental health care. However, no tests of statistical significance were reported for this comparison. The current study builds on the initial evaluation [23] by assessing a broader range of outcomes, including family empowerment and communication, employing a longer follow-up period, and examining the effect of the intervention on both the Veteran and a family member. We hypothesized that family members receiving the intervention would, relative to those randomized to the control group, report greater increases in their perceived efficacy to carry out the tasks targeted by the intervention along with enhanced family empowerment. We also hypothesized that Veterans of family members who received the intervention would report greater increases in perceived family support than those in the control group. Finally, we hypothesized that Veterans and family members in the intervention group would report greater decreases in perceived criticism as well as reactivity to criticism during their conversations.

\section{METHODS}

\section{Participants}

Participants were organized by family-based dyads, each having an OIF/OEF Veteran with probable PTSD along with a family member or partner designated by the Veteran. Inclusion criteria were (1) Veteran of OIF/OEF, (2) positive screen on the PTSD Checklist (PCL) $(\geq 50)$, (3) availability of a family member to participate who has contact with the Veteran three or more times per week, and (4) access to a computer with connection to the Internet. Study recruitment occurred between September 2011 and March 2013.

\section{Procedure}

The Figure summarizes the recruitment flow for the study. Using VA administrative data for fiscal years 2009 and 2010, we identified a pool of Veterans who either screened positive for PTSD or had a PTSD diagnosis assigned during a nonstudy visit in the VA New Jersey Health Care System. Letters introducing the study were mailed to 876 Veterans. After mailing an informational letter to the candidate, telephone contact was attempted to explain the study and assess for eligibility. Telephone contact was established with 278 Veterans and could not be established with 598 Veterans because of returned letters (52) an inability to establish phone contact (546). Interested Veterans who met our inclusion criteria and provided verbal consent then designated a family member or partner to participate in the study. The PCL [24] was administered by telephone to determine whether the participant had probable PTSD (PCL score $\geq 50$ ). Telephone contact was then established with the family member, the study was explained, and verbal informed consent was obtained from the family member. A total of 175 Veterans were not enrolled for reasons described in the Figure, and 103 dyads were enrolled into the study. All study procedures were approved by the VA New Jersey Institutional Review Board, and the study was granted a waiver for signed informed consent.

Participating dyads were then randomly assigned to the intervention or control group (no intervention/assessment only). Randomization was conducted using a blocking factor of PCL severity and a factor of Veteran involvement in mental health treatment within the previous 6 mo. All measures were completed separately by each member of the dyad via online survey. For family members in the intervention group, completion of baseline 

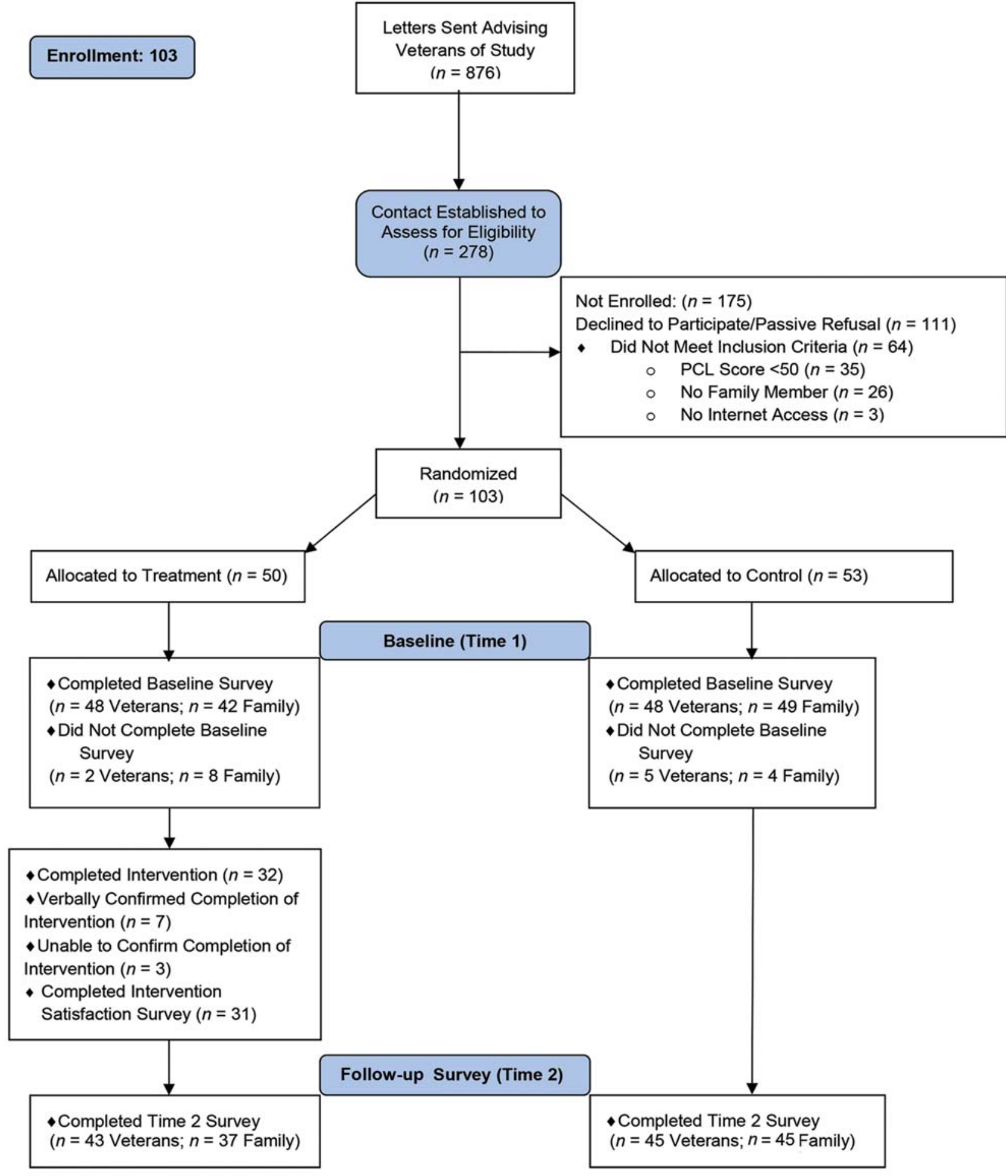

Figure.

Participant flow through the study. PCL $=$ Posttraumatic Stress Disorder Checklist. 
measures directed them to the Family of Heroes Web site to complete the $1 \mathrm{~h}$ intervention. Upon completing the intervention, family members were immediately directed to a postintervention online survey, which assessed intervention satisfaction. Each member of the dyad was separately invited to complete the online follow-up survey 2 mo after baseline. Veterans and family members each received \$25 for baseline surveys and \$35 for 2 mo follow-up surveys. Also, each member of the dyad received a $\$ 10$ bonus at each time point for completing the survey by the specified due date.

\section{Intervention}

The Family of Heroes intervention was developed with input from VA clinicians, Veterans, and family members of Veterans. It was designed to be brief $(1 \mathrm{~h})$ and accessible from computers in users' homes to anyone within the Veterans Integrated Service Network 3 (VISN3) catchment area (areas of New York and New Jersey). The training uses avatar characters that present psychoeducation and engage in simulated conversations concerning postdeployment stress and mental health treatment. The psychoeducation element discusses common symptoms and challenges that can arise during the postdeployment period. The intervention also offers the user a different way to interpret Veterans' behaviors. For example, Veteran isolative behaviors are reframed as possibly wanting to avoid PTSD triggers, rather than the Veteran not wanting to be with family members.

Via three conversation scenarios, the intervention encourages family members to have conversations about key issues that arise during postdeployment. The scenarios provide psychoeducation and allow the user to engage in a simulated conversation by selecting the statements that the avatar family member communicates to his or her Veteran. A key aim of the simulated conversations is to help the family member choose statements that convey curiosity about the Veteran's perspective and empathy and soften the tone of the conversation. This occurs repeatedly throughout the conversation as the scene plays out. A visual meter provides continuous feedback on conversational tone, allowing users to see whether their selected statement escalated or de-escalated the conversation. Each conversational scenario focused on one of three themes: (1) de-escalating an argument, (2) renegotiating household responsibilities, and (3) encouraging VA mental health treatment-seeking. During these scenarios, instruction and practice were provided for communication skills that help de-escalate and soften the tone of communication. At the end of the training, various links were listed to local Veterans' resources (e.g., Veteran Crisis Line) and information for seeking treatment at the local VA.

\section{Measures}

As noted previously, the PCL was administered by telephone at baseline. The PCL is widely used for assessing PTSD symptom severity and has 17 items scored 1 to 5 , yielding a score of 17 to 85 , with higher scores indicating greater symptoms. The cutoff of 50 for probable PTSD is commonly used in studies with servicemember populations [25]. Family members randomized to the intervention completed a satisfaction survey after completing the training. They provided Likert ratings on the training with respect to overall rating of the course, as well as ratings on the degree to which (1) other Veteran family members should take the course and (2) the simulated conversations were realistic.

The following measures were completed by family members at baseline and 2 mo follow-up. Family empowerment was assessed with the 12-item family subscale from the Family Empowerment Scale [26]. Each item was rated from 1 (not true at all) to 5 (very true), resulting in a sum score of 12 to 60, with higher scores indicating greater empowerment. This subscale has been shown to be sensitive to change in a study examining a family intervention [27]. Family members' perceived efficacy to carry out tasks targeted by the intervention was assessed with a 7-item measure, adapted from the initial Family of Heroes study [23]. Sample tasks included recognizing warning signs of postdeployment stress, motivating the Veteran to seek help, and conducting challenging conversations. Perceived ability to perform each task was rated 1 (low) to 4 (very high), yielding a sum score of 7 to 28 , with higher scores indicating greater perceived efficacy.

Veterans completed the following measures at baseline and 2 mo follow-up. Perceived family support was assessed using the family subscale of the Multidimensional Scale for Perceived Social Support [28]. This subscale had four items rated 1 (very strongly disagree) to 7 (very strongly agree), yielding a score of 4 to 28, with higher scores indicating greater perceived support. The Multidimensional Scale for Perceived Social Support, including the perceived social support subscale, has been found to negatively correlate with PTSD in Veteran populations [29] and to be sensitive to change with family 
intervention [30]. Veteran mental health service use during the 2 mo prior to the study was assessed via Veteran self-report for non-VA care and via electronic medical record extraction for VA care.

Veterans and family members each also completed the Perceived Criticism Scale [31-33]. The scale consists of ratings of perceived criticism and reactivity to criticism. For perceived criticism ratings, Veterans completed the following two items: (1) "How critical do you think you are of your family member?" and (2) "How critical do you think your family member is of you?” For reactivity to criticism, Veterans completed the following two items: (1) "When your family member criticizes you, how upset do you get?" and (2) "When you criticize your family member, how upset does he/she get?” Family members also completed these items, but with wording keyed to focus on "your Veteran.” For perceived criticism and reactivity to criticism, items were rated 1 to 10 and were summed to generate a score ranging from 2 to 20 , with higher scores indicating greater perceived problems.

\section{Analyses}

To assess the comparability of the sample at baseline, participants in the intervention and control conditions were compared on demographic characteristics (sex, age, education, employment status, race/ethnicity, marital status, and relationship between members of the dyad [e.g., spouses, parent/child]) as well as the baseline measures described previously. For these analyses, linear variables were examined with analyses of variance (ANOVAs), and categorical variables were examined with chi-square tests for proportions. Analyses of intervention effects used an intent-to-treat approach, analyzing all cases regardless of whether the participant was lost to followup. All outcomes were examined using mixed models, repeated-measures ANOVA. Random effects were specified by subject, with the condition-by-time estimates as the fixed effect of interest.

\section{RESULTS}

As shown in the Figure, 50 dyads were randomized into the intervention group and 53 into the control group. Completion rates for the follow-up survey were greater than 75 percent for Veterans and family members in both conditions. For the intervention group, family member access to the intervention was confirmed electronically
( $n=32$ ) or verbally $(n=7)$, indicating that 78 percent received the intervention.

Table 1 summarizes the demographic characteristics of the Veterans and family member participants. The sample was racially/ethnically diverse, and it is notable that the vast majority of family member participants were either married or living as married. No significant differences between the study conditions emerged on distributions for any of these variables.

A total of 31 family members from the treatment condition completed the postintervention satisfaction survey. The overall ratings for the course were 36.4 percent excellent, 57.6 percent very good, and 6.1 percent good (the numbers add to 100.1 due to rounding). Also, 54.5 percent strongly agreed and 45.5 percent agreed that other families of Veterans should take this course. In

Table 1.

Sample characteristics for Veterans and their designated family member/partner.

\begin{tabular}{|c|c|c|}
\hline Characteristic & $\begin{array}{c}\text { Veteran } \\
n(\%)\end{array}$ & $\begin{array}{c}\text { Family Member } \\
\text { Partner } \\
n(\%)\end{array}$ \\
\hline Female & $18(18.8)$ & $78(85.7)$ \\
\hline \multicolumn{3}{|l|}{ Age (yr) } \\
\hline$<29$ & $31(32.3)$ & $32(35.2)$ \\
\hline $30-36$ & 35 (36.5) & $22(24.2)$ \\
\hline$\geq 37$ & 30 (31.3) & $37(40.7)$ \\
\hline \multicolumn{3}{|l|}{ Education } \\
\hline High School or Less & $13(13.5)$ & $25(27.8)$ \\
\hline Some College & $47(49.0)$ & $23(25.6)$ \\
\hline College Graduate or Higher & $36(37.5)$ & $42(46.7)$ \\
\hline \multicolumn{3}{|l|}{ Employment Status } \\
\hline Full-Time & $51(53.1)$ & $48(53.3)$ \\
\hline Part-Time & $10(10.4)$ & $10(11.1)$ \\
\hline Looking for Work/Disabled/Other & 35 (36.5) & $32(35.6)$ \\
\hline \multicolumn{3}{|l|}{ Race/Ethnicity } \\
\hline White & $50(52.1)$ & $57(63.3)$ \\
\hline Black & $10(10.4)$ & $11(12.2)$ \\
\hline Hispanic/Latino & 30 (31.3) & $20(22.2)$ \\
\hline American Indian & $1(1.0)$ & $2(2.2)$ \\
\hline Asian & $3(3.1)$ & - \\
\hline \multicolumn{3}{|l|}{ Marital Status } \\
\hline Married/Living As & $58(60.4)$ & $56(73.0)$ \\
\hline Never Married & $24(25.0)$ & $17(22.0)$ \\
\hline Divorced/Separated & $14(14.6)$ & $4(5.0)$ \\
\hline \multicolumn{3}{|l|}{ Relationship to Veteran } \\
\hline Spouse/Partner & $65(67.7)$ & - \\
\hline Son/Daughter & $14(14.6)$ & - \\
\hline Parent & $3(3.1)$ & - \\
\hline Other & $13(13.5)$ & - \\
\hline Had Mental Health Visit in Previous 2 mo $^{*}$ & $40(42.1)$ & - \\
\hline \multicolumn{3}{|l|}{ Deployments } \\
\hline Previous Deployments $(n)$ & $1.49 \pm 0.96$ & - \\
\hline Time Since Last Deployment (mo) & $63.65 \pm 30.32$ & - \\
\hline
\end{tabular}


terms of whether the simulated conversations were realistic, 42.4 percent strongly agreed, 45.5 percent agreed, and 12.1 percent disagreed that this was the case.

Table 2 summarizes outcomes relating to communication processes, as reported by the family members and the Veterans. Veterans' report of reactivity to criticism showed a significant time-by-condition effect. Whereas Veterans in the control condition showed no change on this variable, those in the intervention condition showed a decrease of 1.8 points in terms of how they and their family members became upset in response to criticism. No significant effects were observed for ratings of perceived criticism (Veteran or family member report) or reactivity to criticism as reported by the family member.

The reactivity to criticism items reported by the Veteran include one item probing how upset the Veteran becomes in response to criticism and one item on how upset the family member becomes in response to criticism. We conducted post hoc analyses, separately with each of these items, to evaluate whether the Veteran is reporting changes in his or her own reactivity to criticism, the family member's reactivity, or both. These analyses showed a significant time-by-condition interaction for Veteran's report of family member's reactivity $(p=0.02)$, but not for Veteran's own reactivity $(p=0.18)$. Veterans in the intervention condition reported a 1.0 point decrease in their family members' reactivity to criticism, with relatively no change for those in the control group.
Table 3 summarizes outcomes for family perceived efficacy for accomplishing the tasks targeted by the intervention and family empowerment as well as Veterans' ratings of perceived family support. While no condition-bytime effect was observed on the family-perceived efficacy measure, a trend toward significance was observed for family empowerment, indicating a trend for intervention group family members to report increases in family empowerment. Veterans' report of perceived family support showed a significant time-by-condition effect. However, that effect was counter to our second hypothesis, showing that Veterans in the Family of Heroes condition were more likely to report a decrease in perceived family support.

\section{DISCUSSION}

The current study examined a novel approach that targeted the families of Veterans with probable PTSD via a fully automated, interactive Internet-based intervention of $1 \mathrm{~h}$ duration. While the overall pattern of results on the effectiveness of this intervention is mixed, it nevertheless provides an early understanding of this model of intervention. Feasibility for this intervention seemed favorable given the completion rates and the satisfaction ratings.

Table 2.

Summary of outcomes pertaining to communication processes.

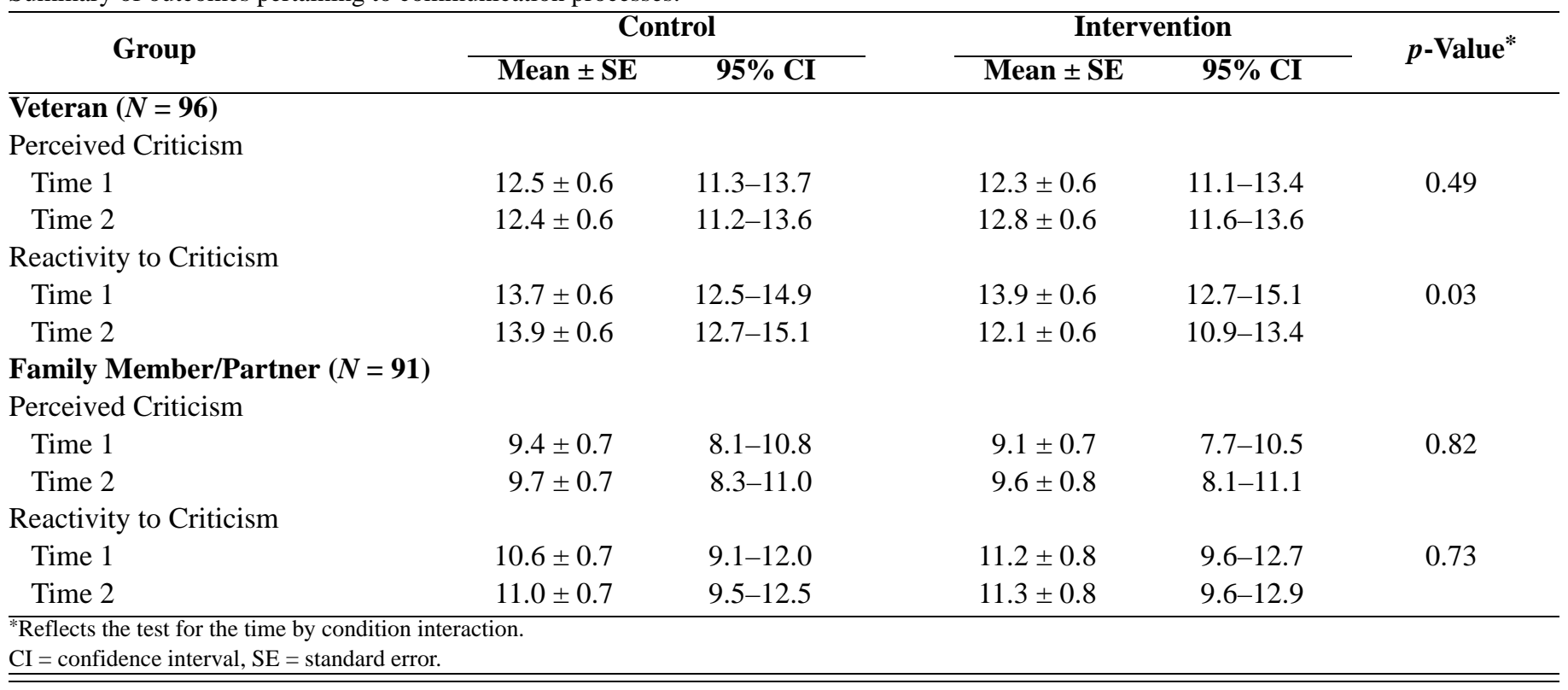


Table 3.

Summary of outcomes providing assistance and support to Veteran.

\begin{tabular}{|c|c|c|c|c|c|}
\hline \multirow{2}{*}{ Group } & \multicolumn{2}{|c|}{ Control } & \multicolumn{2}{|c|}{ Intervention } & \multirow{2}{*}{$p$-Value* } \\
\hline & Mean \pm SE & $95 \%$ CI & Mean \pm SE & 95\% CI & \\
\hline \multicolumn{6}{|c|}{ Family Member/Partner $(N=91)$} \\
\hline \multicolumn{6}{|c|}{ Perceived Efficacy } \\
\hline Time 1 & $19.5 \pm 0.8$ & $18.0-21.0$ & $18.6 \pm 0.8$ & 17.0-20.3 & 0.54 \\
\hline Time 2 & $19.6 \pm 0.8$ & $18.0-21.1$ & $19.5 \pm 0.9$ & $17.8-21.2$ & \\
\hline \multicolumn{6}{|c|}{ Family Empowerment } \\
\hline \multicolumn{6}{|l|}{ Veteran $(N=96)$} \\
\hline \multicolumn{6}{|c|}{ Perceived Family Support } \\
\hline Time 1 & $16.3 \pm 0.8$ & 14.7-17.9 & $18.4 \pm 0.8$ & 16.8-20.1 & 0.04 \\
\hline Time 2 & $17.5 \pm 0.8$ & $15.8-19.1$ & $17.6 \pm 0.9$ & 15.9-19.3 & \\
\hline
\end{tabular}

Based on the skills targeted by the conversational vignettes, it is encouraging that Veterans in the intervention group reported a significant reduction in their family members' reactivity to criticism. This finding shows that a brief, Internet-based intervention for Veterans' family members can lead to behavioral changes that are observable by Veterans who did not themselves participate in the intervention. This is an important outcome for improving postdeployment communication [15], and it is notable that this effect was detectable at 2 mo follow-up. This finding suggests that the intervention may help shape dyadic communication to be less reactive and more adaptive. Family members' level of criticism is a wellestablished predictor of clinical outcomes in a variety of mental disorders [34]. Among individuals with bipolar illness, in which family support also predicts illness trajectory, research has found that feeling upset in response to criticism is an even stronger risk factor for relapse than the level of criticism itself [32]. Because poor family communication has been identified as a major obstacle to Veterans' readjustment [35], this finding, detectable even 2 mo postintervention, is important and merits additional investigation for this model of intervention.

That the same outcome did not emerge as significant when reported by family members likely reflects the fact that these measures are capturing respondents' perceptions of communication, which can certainly differ within dyads [31,33]. It is notable that the current improvements are reported by the Veterans, as they are presumably in a position to observe the softer communication approaches that the intervention targets for the family members. This is consistent with our post hoc analyses showing that Veterans' report of decreased reactivity reflected family members' reactivity (the recipients of the training) more than it did their own reactivity. Ultimately, one would desire reduced reactivity to criticism as reported by both family members and Veterans.

On the other hand, findings showing decreased perceived family support among Veterans in the intervention group are concerning given that perceived social support has been recognized as a key variable in shaping the course of PTSD symptoms [36]. While we cannot explain this finding within the scope of the present study, we can offer some potential interpretative considerations. We note that results of decreased perceived family support are somewhat contradictory given that Veterans in the intervention group observed decreased reactivity to criticism in their family members. Decreased family support also seems inconsistent with the fact that no differences between groups were observed in perceived criticism. Given the complexity of interpersonal relationships, it may be that when the family members became less reactive, this may have been perceived by the Veteran as withdrawal or distancing, leading to the paradoxical outcome of decreased perceived support. On the other hand, the communication skills introduced in Family of Heroes were originally developed in an intervention involving several sessions [37]. These skills are generally thought to require a great deal of practice, and without additional support or guidance, it is possible that some communication components were difficult for families to implement during conversations. Thus, it is not clear whether more 
nuanced changes occurred within dyads that were difficult to assess with our design. For this reason, future research-perhaps through direct observation-is needed to better evaluate the communication changes.

The intervention also provided family members with information on postdeployment stress and simulated practice on conversational strategies. We hypothesized that providing such critical information would improve family members' empowerment and efficacy as well as Veterans' perceived family support. The intervention's trend toward significance for family empowerment was encouraging, but this requires confirmation with future studies employing larger sample sizes.

In contrast with an earlier evaluation of Family of Heroes, current results showed no significant effects on family members' perceived efficacy to carry out the specific tasks to support their Veterans. However, the earlier study assessed this measure 1 mo postintervention [21], while our study examined it at 2 mo postintervention. Also, the two studies' sampling strategies varied: while this study approached family members indirectly (i.e., through Veterans who consented to the study), Albright et al. recruited family members directly (i.e., via online advertisements) [23]. The earlier recruitment approach likely generated a cohort more initially motivated for the intervention.

The current study provides an early assessment of the model of intervention used by Family of Heroes (i.e., brief Internet-based intervention for families), and a number of considerations are proposed for future research. First, it is important to note that the current study was limited by a small sample size, given that a $1 \mathrm{~h}$ self-help intervention is likely to produce small effects on outcomes. Given this, it is notable that a reduction in reactivity to criticism was detectable at 2 mo, but future studies may improve the evaluation of effects with a larger sample size. A second consideration for future research pertains to potential refinements for Family of Heroes or similar models of intervention. Research has demonstrated that Internet-based self-help interventions can produce meaningful clinical effects that are detectable after a follow-up period of several months [20-21]. A review of those interventions shows some differences with the Family of Heroes intervention. Many such interventions involve several modules occurring over several sessions or weeks, which contrast with the current intervention's 1 h duration. Also, Internet-based interventions that have received empirical support tend to include a therapist-support component, such as limited email or telephone support. Meta-analyses have shown that these therapist-support elements tend to produce greater effect sizes for Internet-based interventions [20-21]. These features serve as considerations for enhancing the effect of interventions like Family of Heroes.

As a fourth consideration, future studies can build on the current study's findings by examining different outcomes that may expand our understanding of this brief Internet-based intervention focusing on families. Our study was limited in observing how interaction patterns were changed within the dyads as a result of the intervention. Future research on family interventions can generate important information by directly observing interactions and either analyzing qualitatively or using objective observation coding tools (e.g., Humbad et al. [38]). In addition, measures that assess caregiver knowledge of PTSD and ways of coping with caregiving may be of particular utility [30]. Moreover, a key question for future studies pertains to effects on initiating mental health service use. While our study did collect data on mental health service use, we were not able to appropriately analyze rates of initiating care during the study period because of a sizable percentage of the sample (i.e., 42\%) that had received services in the 2 mo prior to the study. This is an important limitation of our study because it constrained our ability to test the intervention's effect on treatment initiation. If Family of Heroes is shown in future research to help initiate treatment-seeking, it would be a notable finding, showing value as a linkage intervention.

\section{CONCLUSIONS}

In summary, the current study provides an early understanding of a brief model of intervention for Veterans' families. Results showed that the intervention produced a reduction in Veterans' report on the level of reactivity to criticism in the dyad, along with a trend for improved family empowerment. If the current results relating to family empowerment and reactivity to criticism are confirmed in future studies, it would indicate that a low-intensity, self-guided intervention can achieve potentially beneficial effects on families of returning servicemembers experiencing postdeployment reactions. This is particularly notable given that this intervention is publicly available and therefore has the potential for a 
very high level of uptake among Veterans' families. However, during a time when telehealth interventions are rapidly growing, the current findings pertaining to decreased perceived family support (as well as the null findings) raise cautions about the effect of low-dose interventions. Thus, the current study points to critical questions that can help guide future intervention development, research design, and ultimately health policy. What were some of the actual changes in communication patterns that occurred among recipients in this intervention? Would an increased intervention dose (e.g., more sessions, therapist support) enhance outcomes? Can the intervention lead to initiation of mental health treatment? Future research, with designs that address these questions, is critical for guiding ongoing efforts to reach and assist Veterans and their families with online interventions.

\section{ACKNOWLEDGMENTS}

\section{Author Contributions:}

Study concept and design: A. Interian, A. Kline, D. Perlick, M. F. Goldstein, M. Losonczy.

Acquisition of data: A. Interian, A. Kline, K. Hennessy, L. St. Hill. Analysis and interpretation of data: A. Interian, A. Kline, D. Perlick, L. Dixon, A. Feder, M. D. Weiner, M. F. Goldstein, M. Losonczy.

Drafting of manuscript: A. Interian, A. Kline, D. Perlick, M. F. Goldstein, M. D. Weiner.

Statistical analysis: A. Interian, A. Kline, M. D. Weiner, D. Perlick. L. Dixon.

Obtained funding: A. Interian, A. Kline, D. Perlick, M. F. Goldstein, M. Losonczy, A. Feder.

Administrative and material support: K. Hennessy, L. St. Hill, A. Feder.

Financial Disclosures: The authors have declared that no competing interests exist.

Funding/Support: This material was based on work supported by the VISN3 Mental Illness Research, Education, and Clinical Center. This material is the result of work supported with resources and the use of facilities at the VA New Jersey Healthcare System.

Additional Contributions: VISN3 has now become Veterans Integrated Service Network 2 Downstate, as part of the VA's national restructuring.

Institutional Review: All study procedures were approved by the VA New Jersey Institutional Review Board, and the study was granted a waiver for signed informed consent.

Participant Follow-Up: A copy of this publication will be made available to participants upon request.

\section{REFERENCES}

1. Interian A, Kline A, Janal M, Glynn S, Losonczy M. Multiple deployments and combat trauma: Do homefront stressors increase the risk for posttraumatic stress symptoms? J Trauma Stress. 2014;27(1):90-97. [PMID:24464407] http://dx.doi.org/10.1002/jts.21885

2. Sayers SL, Farrow VA, Ross J, Oslin DW. Family problems among recently returned military veterans referred for a mental health evaluation. J Clin Psychiatry. 2009;70(2): 163-70. [PMID:19210950] http://dx.doi.org/10.4088/JCP.07m03863

3. Kaniasty K, Norris FH. Longitudinal linkages between perceived social support and posttraumatic stress symptoms: Sequential roles of social causation and social selection. J Trauma Stress. 2008;21(3):274-81. [PMID:18553415] http://dx.doi.org/10.1002/jts.20334

4. Sayers SL. Family reintegration difficulties and couples therapy for military veterans and their spouses. Cogn Behav Pract. 2011;18(1):108-19. http://dx.doi.org/10.1016/j.cbpra.2010.03.002

5. Adler AB, Britt TW, Castro CA, McGurk D, Bliese PD. Effect of transition home from combat on risk-taking and health-related behaviors. J Trauma Stress. 2011;24(4):38189.

[PMID:21818784]

http://dx.doi.org/10.1002/jts.20665

6. Brewin CR, Andrews B, Valentine JD. Meta-analysis of risk factors for posttraumatic stress disorder in trauma-exposed adults. J Consult Clin Psychol. 2000;68(5):748-66.

[PMID:11068961]

http://dx.doi.org/10.1037/0022-006X.68.5.748

7. Saltzman WR, Lester P, Beardslee WR, Layne CM, Woodward K, Nash WP. Mechanisms of risk and resilience in military families: Theoretical and empirical basis of a family-focused resilience enhancement program. Clin Child Fam Psychol Rev. 2011;14(3):213-30. [PMID:21655938] http://dx.doi.org/10.1007/s10567-011-0096-1

8. Renshaw KD, Rodrigues CS, Jones DH. Psychological symptoms and marital satisfaction in spouses of Operation Iraqi Freedom veterans: Relationships with spouses' perceptions of veterans' experiences and symptoms. J Fam Psychol. 2008;22(4):586-94. [PMID:18729672] http://dx.doi.org/10.1037/0893-3200.22.3.586

9. Riggs DS, Byrne CA, Weathers FW, Litz BT. The quality of the intimate relationships of male Vietnam veterans: Problems associated with posttraumatic stress disorder. J Trauma Stress. 1998;11(1):87-101. [PMID:9479678] http://dx.doi.org/10.1023/A:1024409200155

10. Beckham JC, Roodman AA, Barefoot JC, Haney TL, Helms MJ, Fairbank JA, Hertzberg MA, Kudler HS. Interpersonal and self-reported hostility among combat veterans 
with and without posttraumatic stress disorder. J Trauma Stress. 1996;9(2):335-42. [PMID:8731551]

http://dx.doi.org/10.1002/jts.2490090214

11. Monson CM, Fredman SJ, Adair KC. Cognitive-behavioral conjoint therapy for posttraumatic stress disorder: Application to operation Enduring and Iraqi Freedom veterans. J Clin Psychol. 2008;64(8):958-71. [PMID:18613094] http://dx.doi.org/10.1002/jclp.20511

12. Christensen A, Jacobson NS. Acceptance and change in couple therapy: A therapist's guide to transforming relationships. New York (NY): W. W. Norton \& Company; 1998.

13. Fox S, Rainie L. The Web at 25 in the U.S. [Internet]. Washington (DC): Pew Research Center; 2014. Available from: http://www.pewinternet.org/files/2014/02/PIP 25thanniversary-of-the-Web 0227141.pdf

14. Fox S, Duggan M. Health online 2013 [Internet]. Washington (DC): Pew Research Center; 2013. Available from: http://www.pewinternet.org/files/old-media//Files/Reports/ PIP HealthOnline.pdf

15. Tsai J, Harpaz-Rotem I, Pietrzak RH, Southwick SM. The role of coping, resilience, and social support in mediating the relation between PTSD and social functioning in veterans returning from Iraq and Afghanistan. Psychiatry. 2012; 75(2):135-49. [PMID:22642433]

http://dx.doi.org/10.1521/psyc.2012.75.2.135

16. Sadler AG, Mengeling MA, Torner JC, Smith JL, Franciscus CL, Erschens HJ, Booth BM. Feasibility and desirability of Web-based mental health screening and individualized education for female OEF/OIF reserve and national guard war veterans. J Trauma Stress. 2013;26(3):401-4.

[PMID:23696367] http://dx.doi.org/10.1002/jts.21811

17. Makin-Byrd K, Gifford EV, McCutcheon S, Glynn S. Family and couples treatment for newly returning veterans. Prof Psychol Res Pr. 2011;42(1):47-55. http://dx.doi.org/10.1037/a0022292

18. Sherman MD. Updates and five-year evaluation of the S.A.F.E. program: A family psychoeducational program for serious mental illness. Community Ment Health J. 2006; 42(2):213-19. [PMID:16404684] http://dx.doi.org/10.1007/s10597-005-9018-3

19. Adler AB, Bliese PD, McGurk D, Hoge CW, Castro CA. Battlemind debriefing and battlemind training as early interventions with soldiers returning from Iraq: Randomization by platoon. J Consult Clin Psychol. 2009;77(5): 928-40. [PMID:19803572] http://dx.doi.org/10.1037/a0016877

20. Barak A, Hen L, Boniel-Nissima M, Shapiraa N. A comprehensive review and a meta-analysis of the effectiveness of Internet-based psychotherapeutic interventions. J Technol Hum Serv. 2008;26(2-4):109-60. http://dx.doi.org/10.1080/15228830802094429
21. Spek V, Cuijpers P, Nyklícek I, Riper H, Keyzer J, Pop V. Internet-based cognitive behaviour therapy for symptoms of depression and anxiety: A meta-analysis. Psychol Med. 2007;37(3):319-28. [PMID:17112400] http://dx.doi.org/10.1017/S0033291706008944

22. Van Voorhees BW, Gollan J, Fogel J. Pilot study of Internet-based early intervention for combat-related mental distress. J Rehabil Res Dev. 2012;49(8):1175-90. [PMID:23341310] http://dx.doi.org/10.1682/JRRD.2011.05.0095

23. Albright G, Goldman R, Shockley KM, McDevitt F, Akabas S. Using an avatar-based simulation to train families to motivate veterans with post-deployment stress to seek help at the VA. Games Health J. 2012;1(1):21-28. [PMID:26196429] http://dx.doi.org/10.1089/g4h.2011.0003

24. Blanchard EB, Jones-Alexander J, Buckley TC, Forneris CA. Psychometric properties of the PTSD Checklist (PCL). Behav Res Ther. 1996;34(8):669-73. [PMID:8870294] http://dx.doi.org/10.1016/0005-7967(96)00033-2

25. Brewin CR. Systematic review of screening instruments for adults at risk of PTSD. J Trauma Stress. 2005;18(1):53-62. [PMID:16281196]

http://dx.doi.org/10.1002/jts.20007

26. Koren PE, DeChillo N, Friesen BJ. Measuring empowerment in families whose children have emotional disabilities: A brief questionnaire. Rehabil Psychol. 1992;37(4): 305-21. http://dx.doi.org/10.1037/h0079106

27. Dixon L, Lucksted A, Stewart B, Burland J, Brown CH, Postrado L, McGuire C, Hoffman M. Outcomes of the peer-taught 12-week family-to-family education program for severe mental illness. Acta Psychiatr Scand. 2004; 109(3):207-15. [PMID:14984393] http://dx.doi.org/10.1046/j.0001-690X.2003.00242.x

28. Zimet GD, Dahlem NW, Zimet SG, Farley GK. The Multidimensional Scale of Perceived Social Support. J Pers Assess. 1988;52(1):30-41. http://dx.doi.org/10.1207/s15327752jpa5201 2

29. Wilcox SA. Social relationships and PTSD symptomatology in combat veterans. Psychol Trauma. 2010;2(3):175-82. http://dx.doi.org/10.1037/a0019062

30. Fischer EP, Sherman MD, Han X, Owen RR Jr. Outcomes of participation in the REACH multifamily group program for veterans with PTSD and their families. Prof Psychol Res Pr. 2013;44(3):127-34. http://dx.doi.org/10.1037/a0032024

31. Renshaw KD. The predictive, convergent, and discriminant validity of perceived criticism: A review. Clin Psychol Rev. 2008;28(3):521-34. [PMID:17913319] http://dx.doi.org/10.1016/j.cpr.2007.09.002

32. Miklowitz DJ, Wisniewski SR, Miyahara S, Otto MW, Sachs GS. Perceived criticism from family members as a 
predictor of the one-year course of bipolar disorder. Psychiatry Res. 2005;136(2-3):101-11. [PMID:16023735]

http://dx.doi.org/10.1016/j.psychres.2005.04.005

33. Hooley JM, Teasdale JD. Predictors of relapse in unipolar depressives: Expressed emotion, marital distress, and perceived criticism. J Abnorm Psychol. 1989;98(3):229-35.

[PMID:2768657]

http://dx.doi.org/10.1037/0021-843X.98.3.229

34. Barrowclough C, Hooley JM. Attributions and expressed emotion: A review. Clin Psychol Rev. 2003;23(6):849-80. [PMID:14529701] http://dx.doi.org/10.1016/S0272-7358(03)00075-8

35. Bowling UB, Sherman MD. Welcoming them home: Supporting service members and their families in navigating the tasks of reintegration. Prof Psychol Res Pr. 2008;39(4): 451-8. http://dx.doi.org/10.1037/0735-7028.39.4.451

36. Bonanno GA. Loss, trauma, and human resilience: Have we underestimated the human capacity to thrive after extremely aversive events? Am Psychol. 2004;59(1):20-8. [PMID:14736317] http://dx.doi.org/10.1037/0003-066X.59.1.20

37. Mueser KT, Glynn SM, Liberman RP. Behavioral family management for serious psychiatric illness. New Dir Ment
Health Serv. 1994;(62):37-50. [PMID:7935286]

http://dx.doi.org/10.1002/yd.23319946206

38. Humbad MN, Donnellan MB, Klump KL, Burt SA. Development of the Brief Romantic Relationship Interaction Coding Scheme (BRRICS). J Fam Psychol. 2011;25(5): 759-69. [PMID:21875192] http://dx.doi.org/10.1037/a0025216

Submitted for publication November 14, 2014. Accepted in revised form October 5, 2015.

This article and any supplementary material should be cited as follows:

Interian A, Kline A, Perlick D, Dixon L, Feder A, Weiner MD, Goldstein MF, Hennessy K, St. Hill L, Losonczy M. Randomized controlled trial of a brief Internet-based intervention for families of Veterans with posttraumatic stress disorder. J Rehabil Res Dev. 2016;53(5):629-40. http://dx.doi.org/10.1682/JRRD.2014.10.0257

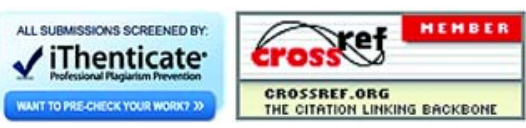

